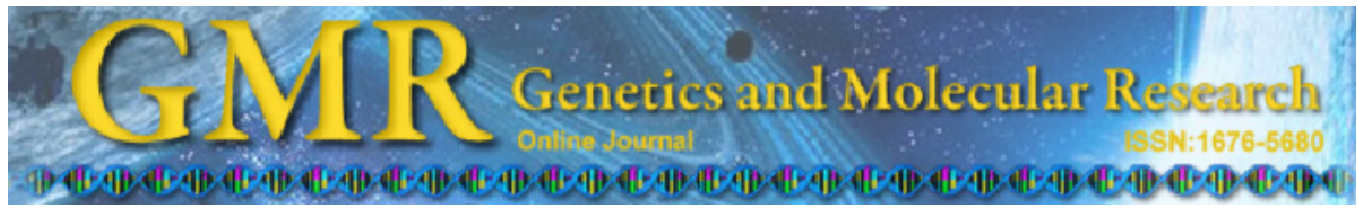

\title{
Does copper stress lead to spindle misposition-dependent cell cycle arrest?
}

\author{
C. Tarhan and A.T. Sarikaya
}

Department of Molecular Biology and Genetics, Faculty of Science, Istanbul University, Vezneciler, Istanbul, Turkey

Corresponding author: C. Tarhan

E-mail: cagataytarhan@yahoo.com

Genet. Mol. Res. 11 (4): 3824-3834 (2012)

Received March 26, 2012

Accepted May 31, 2012

Published October 25, 2012

DOI http://dx.doi.org/10.4238/2012.October.25.1

\begin{abstract}
Because of its specific electrochemical properties, copper is an essential heavy metal for living organisms. As with other heavy metals, high levels can provoke damage. We examined gene expression under copper stress in wild-type fission yeast (Schizosaccharomyces pombe) through differential display. After the $\mathrm{EC}_{50}$ concentration of $\mathrm{CuSO}_{4}$ was determined as $50 \mu \mathrm{M}$, total RNA was isolated from cells treated or not with copper. The expression level of SPCC1682.13, ppk1, $\mathrm{SPBC} 2 \mathrm{~F} 12.05 \mathrm{c}$, and adg2 genes increased significantly under copper stress. Considering the functions of these genes are related to the cell cycle, cell division and chromosome dynamics, we hypothesize that retardation of the cell cycle under copper stress is relevant to the events that depend on the functions of these genes.
\end{abstract}

Key words: Schizosaccharomyces pombe; Copper stress; Cell cycle 


\section{INTRODUCTION}

Copper ions are essential because their coordination and redox properties allow them to participate in important metabolic reactions, such as the destruction of reactive oxygen species and the synthesis of ATP, the neurotransmitter dopamine, and connective tissue (Waggoner et al., 1999; Theophanides and Anastassopoulou, 2002). However, due to the redox chemistry of $\mathrm{Cu}$, it is a potent toxin at elevated concentrations, and organisms utilize homeostatic mechanisms to tightly control both the intracellular concentration and activity of $\mathrm{Cu}$. Because of its toxic properties, copper is involved in many diseases such as Alzheimer's, amyotrophic lateral sclerosis and Menkes syndrome (Karlström and Levine, 1991; Pena et al., 1999; O'Connor, 2001). In recent years, many proteins that function in copper uptake, distribution and detoxification processes have been determined as a result of studies especially with the budding yeast, Saccharomyces cerevisiae. Although considerable progress has been made regarding copper metabolism in eukaryotes, we still need to explore new genes/proteins that have a direct or indirect role in copper metabolism. For example, recently, X-linked inhibitor of apoptosis protein, which is an inhibitor of apoptosis by binding to and inhibiting the catalytic activity of several caspases, has been found to play an important role in intracellular copper homeostasis. The role of this protein in copper metabolism was determined in the study of copper toxicosis in affected Bedlington terriers (Burstein et al., 2004). Thus, new proteins that affect copper incorporation, distribution or intoxication can be found, and for this purpose, molecular techniques that are especially useful in exploring new genes can be used.

In this study, we aimed to determine the genes whose expressions are upregulated as a result of elevated levels of copper. For this purpose, the unicellular ascomycete fungus Schizosaccharomyces pombe was used. S. pombe is a fission yeast sharing many features with cells of more complicated eukaryotes. That is why it has served as an excellent model organism for the study of cell cycle control, mitosis and meiosis, DNA repair and recombination, and the checkpoint controls important for genome stability. Differential display (DD) was performed to determine the gene expression profiles of the cells under copper stress. DD is a practical, relatively inexpensive assay that is especially important in exploring new genes (Ivanova and Ivanov, 2002). Differential expression patterns of genes were confirmed by quantitative real-time PCR. We found four genes whose expression increased in relation to each other under copper stress. We then proposed a scenario where metal stress could cause cell cycle arrest, and we tested this hypothesis by controlling the expression of a cell cycle regulatory gene.

\section{MATERIAL AND METHODS}

\section{Determination of $\mathrm{EC}_{50}$ of copper}

The half-maximal effective concentration $\left(\mathrm{EC}_{50}\right)$ of copper was determined in wildtype $S$. pombe (Lindner str. liquefaciens, $972 \mathrm{~h}$-) cells; $10^{6}$ cells $/ \mathrm{mL}$ were incubated in Edinburgh Minimal Medium (EMM) containing 0, 25, 50, and $100 \mu \mathrm{M} \mathrm{CuSO}_{4}$ and grown for $24 \mathrm{~h}$ at $30^{\circ} \mathrm{C}$, with orbital shaking at $180 \mathrm{rpm}$. At the end of incubation, cells were counted and the copper concentration that killed half of these cells was determined as the $\mathrm{EC}_{50}$. 


\section{Total RNA isolation and cDNA synthesis}

The genes whose expression increased as a result of copper stress were determined mainly using DD, a technique originally developed by Liang and Pardee (2003). First, total RNAs from the cells grown in $\mathrm{EMM}$ with $\mathrm{CuSO}_{4}$ at the $\mathrm{EC}_{50}$ and from the control cells were isolated using a total RNA isolation kit (GenElute ${ }^{\mathrm{TM}}$ Mammalian Total RNA Miniprep kit, Sigma). Cells were grown for $24 \mathrm{~h}$ at $30^{\circ} \mathrm{C}$, with orbital shaking at $180 \mathrm{rpm}$, and harvested by centrifugation and then washed with distilled water twice. Cells were resuspended in lysis buffer and disrupted by vortexing with acid-washed glass beads $(0.50 \mathrm{~mm}$ in diameter) for 10 min at 60-s intervals, interspersed with periods of cooling in an ice-bath. Cellular debris was removed by centrifugation at $7500 \mathrm{rpm}$, at $4^{\circ} \mathrm{C}$ for $5 \mathrm{~min}$. The supernatant was collected and processed according to the kit manual, and the resulting total RNAs were analyzed electrophoretically and spectrophotometrically.

Total RNAs were converted to cDNA using a cDNA synthesis kit (Takara RNA PZR kit, AMV, Ver. 3.0) according to the manufacturer protocol. In first-strand cDNA synthesis, one base-anchored oligo(dT) primers used for reverse transcription were designed according to Tawe et al. (1998). After first-strand cDNA sythesis, double-stranded cDNAs were polymerized with universal random primers (Table 1).

\begin{tabular}{|c|c|c|}
\hline \multirow[t]{3}{*}{ Single-base substition oligo(dT) primers } & H-T11A & \begin{tabular}{|c|} 
5'AAGCTTTTTTTTTTA-3' \\
\end{tabular} \\
\hline & $\mathrm{H}-\mathrm{T} 11 \mathrm{C}$ & 5'-AAGCTTTTTTTTTTTC-3' \\
\hline & H-T11G & 5'-AAGCTTTTTTTTTTTG-3' \\
\hline \multirow{8}{*}{ (H-AP) universal random primers (13-mer) } & H-AP1 & 5'-AAGCTTGATTGCC-3' \\
\hline & H-AP2 & 5'-AAGCTTCGACTGT-3' \\
\hline & H-AP3 & 5'-AAGCTTTGGTCAG-3' \\
\hline & H-AP4 & 5'-AAGCTTCTCAACG-3' \\
\hline & H-AP5 & 5'-AAGCTTAGTAGGC-3' \\
\hline & H-AP6 & 5'-AAGCTTCGACCAT-3' \\
\hline & H-AP7 & 5'-AAGCTTAACGAGG-3' \\
\hline & H-AP8 & 5'-AAGCTTTTACCGC-3' \\
\hline
\end{tabular}

Twenty-four PCRs were performed with three oligo(dT) primers combined with eight random primers (HAP1-8). Two-microliter cDNA template was used directly in a $20-\mu \mathrm{L}$ reaction mixture containing $1 \mathrm{X}$ Taq buffer with $\mathrm{KCl}, 0.2 \mathrm{mM}$ dNTP mix, $1.5 \mathrm{mM} \mathrm{MgCl}, 1 \mathrm{U}$ Taq DNA polymerase (Fermentas), $0.5 \mu \mathrm{M}$ random primer, and $0.5 \mu \mathrm{M}$ of the same anchored oligo(dT) primer used in first-strand cDNA synthesis. Random primers were designed according to Tawe et al. (1998). Subsequent to an initial 30-s denaturation at $94^{\circ} \mathrm{C}, 40$ amplification cycles were performed as follows: $30 \mathrm{~s}$ at $94^{\circ} \mathrm{C}, 2 \mathrm{~min}$ at $40^{\circ} \mathrm{C}, 30 \mathrm{~s}$ at $72^{\circ} \mathrm{C}$. This was followed by a 5 -min final extension at $72^{\circ} \mathrm{C}$ and hold at $4{ }^{\circ} \mathrm{C}$.

\section{Polyacrylamide gel electrophoresis and silver staining}

PCR products were separated on $6 \%$ nondenaturing polyacrylamide gels $(16.5 \times 28.0$ x $0.75 \mathrm{~mm}$ ). The gels were prerun for 30 min prior to loading, and electrophoresis was performed in $1 \mathrm{X}$ TBE buffer at $8 \mathrm{~W}$ for $15 \mathrm{~h}$. A volume of $12 \mu \mathrm{L}$ PCR products was mixed with $4 \mu \mathrm{L}$ xylene-cyanol loading dye in microcentrifuge tubes and incubated at $95^{\circ} \mathrm{C}$ for $5 \mathrm{~min}$ for denaturation. The tubes were then chilled on ice immediately, and after $2 \mathrm{~min}$, the mixture was loaded on gels. Gel electrophoresis were done at $120 \mathrm{~V}, 1 \mathrm{X}$ TBE buffer, and run for $15 \mathrm{~h}$. 
The DNA bands were visualized by silver staining (Tullo and Sbisà, 2002). First, the gels were shaken in a mixture containing $10 \%$ ethanol and $1 \%$ acetic acid at room temperature, at $50 \mathrm{rpm}$ for $10 \mathrm{~min}$, and then washed with ultrapure water for $1 \mathrm{~min}$. The gels were then shaken in 5\% nitric acid solution for $3 \mathrm{~min}$ and washed again. Gels were transferred to ice-cold $0.2 \%$ silver nitrate solution with orbital shaking for $40 \mathrm{~min}$. Afterwards, gels were washed twice and incubated in a solution containing $30 \mathrm{~g} / \mathrm{L}$ sodium carbonate and $0.2 \%$ formaldehyde. Once bands appeared, the gels were incubated in stop solution (5\% acetic acid) for $1 \mathrm{~min}$. Gels were washed with ultrapure water and kept at $4^{\circ} \mathrm{C}$.

\section{Recovery of cDNA bands}

DNA bands were excised with a sterile razor and homogenized in microcentrifuge tubes with a 150- $\mu \mathrm{L}$ phenol/chloroform/isoamyl alcohol (25:24:1) mixture. After $30 \mathrm{~min}$, the tubes were boiled in water for $15 \mathrm{~min}$ and centrifuged at 14,000 rpm for $1 \mathrm{~min}$. Supernatant was transferred to a new tube and mixed with 3.5 volumes $100 \%$ ethanol and 1/10 volume 2.5 $\mathrm{M}$ sodium acetate, $\mathrm{pH}$ 5.2. The mixture was incubated at $-70^{\circ} \mathrm{C}$ for $30 \mathrm{~min}$ and then centrifuged at 15,000 rpm for $10 \mathrm{~min}$. The pellet was resuspended in $100 \mu \mathrm{L} 75 \%$ ethanol and again centrifuged at 15,000 rpm for $5 \mathrm{~min}$. The pellet was dried completely and resuspended in 15 $\mathrm{mL}$ ultrapure water. A $5-\mu \mathrm{L}$ sample from each tube was loaded on $2 \%$ agarose gels, and successfully recovered DNA bands were confirmed. Reamplified PCR products were sequenced using the corresponding HAP primers. Sequencing was performed commercially (Iontek A.S., Turkey) with an ABI PRISM 310 Genetic Analyzer using the DYEnamic ET Terminator Cycle Sequencing kit (Amersham). Sequence data were then subjected to BLASTX (Swiss-Prot) and BLASTN (RefSeq mRNA) searches of the $S$. pombe genome database at the National Center for Biotechnology Information (http://www.ncbi nlm.nih.gov/).

\section{Real-time PCR analysis}

The DD results were confirmed by real-time PCR analysis performed using SYBR Green I fluorescent dye. Expression levels were normalized against the reference gene act1. Relative gene expression was determined according to the method of Pfaffl (2001). Total RNA isolation and cDNA synthesis were done as described above, and real-time experiments were performed using Stratagene MX3005P. Primers were designed according to manufacturer recommendations and the Primer 3 software (Table 2).

\begin{tabular}{|c|c|c|c|c|}
\hline Gene name & Primers & $\% \mathrm{GC}$ & $\operatorname{Tm}\left({ }^{\circ} \mathrm{C}\right)$ & Product size $(b p)$ \\
\hline \multirow[t]{2}{*}{ act1 } & F: ACTATGTATCCCGGTATTGCC & 47.6 & 60.6 & \multirow[t]{2}{*}{108} \\
\hline & R: GACAGAGTATTTACGCTCAGG & 47.6 & 59.6 & \\
\hline \multirow[t]{2}{*}{$\mathrm{SPBC} 2 \mathrm{~F} 12.05 \mathrm{c}$} & F: TCACTTAATGCGCTCACTCC & 50 & 59.03 & \multirow[t]{2}{*}{132} \\
\hline & R: TTCTTCAAGGCGGTTTTTCT & 40 & 58.95 & \\
\hline \multirow[t]{2}{*}{ laf2 } & F: TGGCTTCGACTCTTCGTCTT & 50 & 60.13 & \multirow[t]{2}{*}{127} \\
\hline & R: CGACTAGCCCTTTGAGCATC & 55 & 59.98 & \\
\hline \multirow[t]{2}{*}{$\operatorname{adg} 2$} & F: CAAACCAACAGTGGTCATGC & 60 & 50 & \multirow[t]{2}{*}{136} \\
\hline & R: TGCCTGTCGAGACACTAACG & 60 & 55 & \\
\hline \multirow[t]{2}{*}{ SPAC110.01 } & F: TCATGTGGATCGCCCTTGTTA & 40 & 60 & \multirow[t]{2}{*}{129} \\
\hline & R: AGATACCCAGCCAACATTGC & 45 & 59 & \\
\hline
\end{tabular}

$\mathrm{F}=$ forward $\mathrm{R}=$ reverse $\% \mathrm{GC}=$ percent guanine-cytosine content $\mathrm{Tm}=$ melting temperature. 
Real-time PCR experiments were performed using a quantitative PCR kit (SYBR Premix Ex Taq, Takara). The reaction mixture was prepared as described by the manufacturer. PCR conditions were the same as mentioned above.

\section{RESULTS}

\section{Determination of $\mathrm{EC}_{50}$ of copper}

$\mathrm{EC}_{50}$ value of copper was determined in EMM containing different concentrations of $\mathrm{CuSO}_{4}$. The number of the cells grown in EMM containing $50 \mu \mathrm{M} \mathrm{CuSO}_{4}$ was half of the control group (Figure 1). Thus, this concentration value was chosen for copper stress condition in subsequent experiments.

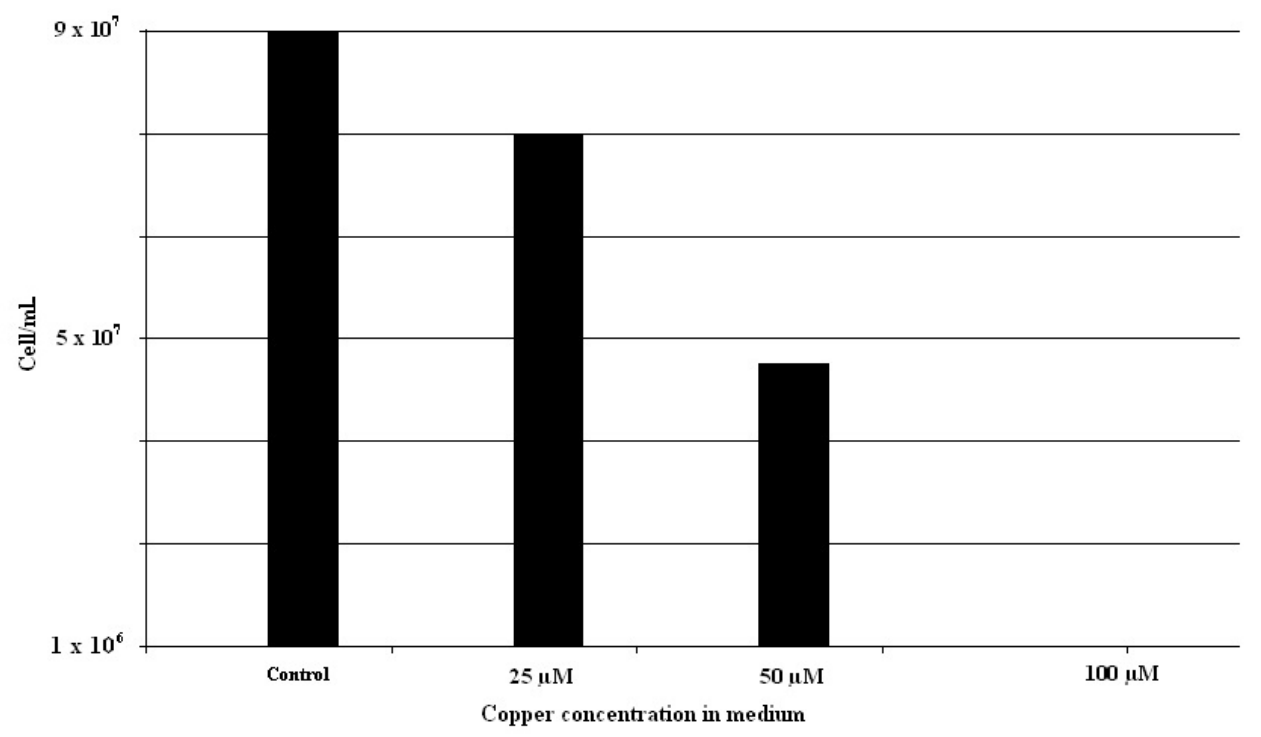

Figure 1. Determination of $\mathrm{EC}_{50}$ value of $\mathrm{CuSO}_{4}$. Cells were grown in Edinburgh Minimal Medium, which contains different concentrations of copper. Fifty micromolar $\mathrm{CuSO}_{4}$ was sufficient to inhibit half of the cells of the control group.

\section{Polyacrylamide electrophoresis of cDNAs}

Total RNAs from the control group and from the cells grown in EMM containing 50 $\mu \mathrm{M} \mathrm{CuSO}_{4}$ were isolated and converted to cDNA. Using combinations of 3 different anchored primers [oligo(dT)A, oligo(dT)C and oligo(dT)G)] and 8 universal random primers, 48 PCR products were run on polyacrylamide gels, and gels were stained with silver stained as described above. DNAs from the control group and from stressed cells that were polymerized with same primer combination were loaded on gels side by side, and differentiated bands were easily determined (Figure 2). The bands belonging to genes whose expression was induced or increased under copper stress were excised from gels as outlined in Material and Methods. 

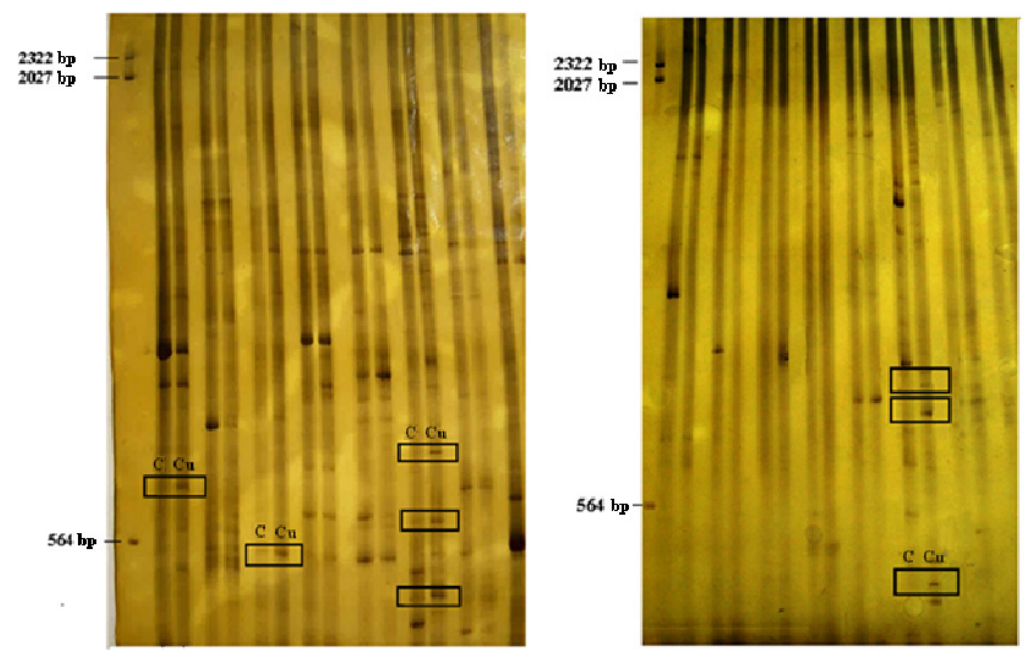

Figure 2. cDNA bands that amplified with PCR using different combinations of anchored and universal random primers. The gel that has DNA bands amplified using combinations of oligo(dT)C-anchored primer and 8 universal primers is seen on the left and the gel of oligo(dT)G-anchored primer and 8 universal primer combinations is seen on the right. Some of the differentiated bands were shown in rectangles. $\mathrm{C}=$ control group; $\mathrm{Cu}=$ copper stress.

\section{Recovery of cDNA bands and DNA sequencing}

The 25 recovered cDNA bands were sent for DNA sequencing, and sequenced DNAs were analyzed with the Chromas 2.32 software. Twenty of 25 bands were eliminated because of their inadequate quantity for sequencing or due to inability to match to the $S$. pombe genome. The remaining 5 genes were significantly matched to the genome and are shown in Table 3.

Table 3. Gene equivalents and E values of cDNA sequences that matched to the Schizosaccharomyces pombe
genome.
\begin{tabular}{lllll}
\hline Band No. Size of the queried cDNA band (bp) & E value & Gene name & Function \\
\hline 1 & 150 & $9.2 \mathrm{e}-08$ & SPBC1348.01 & S. pombe-specific DUF999 protein family 5. Unknown function \\
2 & 139 & $9.2 \mathrm{e}-08$ & SPBC2F12.05c & Sterol binding ankyrin repeated protein \\
3 & 770 & $3.8 \mathrm{e}-5$ & SPAC110.01 & Predicted serine/threonine protein kinase, Ppk1 \\
4 & $1.4 \mathrm{e}-5$ & SPCC1682.13 & Clr6-associated factor 2, Laf2, SWIRM domain protein \\
5 & 737 & $1.1 \mathrm{e}-5$ & SPAC19G12.16c & Conserved fungal protein, adg2 \\
\hline
\end{tabular}

One of the matched gene products belonged to the S. pombe-specific DUF999 protein family with unknown function. The other gene product was the sterol binding ankyrin repeat protein. This well-characterized protein has roles in cellular response to stress, endocytosis, exocytosis, steroid metabolic process, and sterol transport. The third gene product was a predicted serine/threonine protein kinase, Ppk1. The protein has two orthologs in $S$. cerevisiae, YOR233W and YPL141C. YOR233W (KIN4) is a serine/threonine protein kinase that inhibits the mitotic exit network (MEN) when the spindle position checkpoint is activated. YPL141C is said to be similar to KIN4. The other gene product was Clr6-associated factor 
2 (Laf2), which has a role in chromatin remodeling and histone deacetylation. The last gene product was a conserved fungal protein, Adg2. The protein functions in the cell-cell separation process during cytokinesis.

\section{Confirmation of DD results}

The differential expression of the genes in Table 1 was examined by quantitative realtime PCR using gene-specific primer sets (Table 2, in Material and Methods). The expression increase of the SPCC1682.13, SPBC2F12.05c, adg2 genes was moderate (1.6-, 1.6- and 1.4-fold, respectively), while ppk1 showed significant increase in gene expression (5.8-fold). SPBC1348.01 expression seemed to be increased (0.9-fold) and we assumed that its DD result was a false positive (Table 4). We also investigated dis1 gene expression. dis1 is a microtubule-associated protein that has a role in sister chromatid separation. Our findings pointed out that chromosome segregation or spindle pole body positioning abnormalities could be responsible for cell growth retardation, which depends on delayed mitosis. For this reason, we examined the expression of a gene that is known as a component of the cell cycle machinery. Thus, we chose dis 1 as a candidate gene and monitored its expression under copper stress (see Discussion for details). We found that dis1 was negatively regulated relative to the control group (0.7-fold). The results are summarized in Table 4 .

\begin{tabular}{|c|c|}
\hline Gene & Fold increase in gene expression \\
\hline SPCC1682.13 (laf2) & $1.6 \pm 0.13$ \\
\hline $\mathrm{SPBC} 2 \mathrm{~F} 12.05 \mathrm{c}$ (sterol binding ankyrin repeat protein) & $1.4 \pm 0.09$ \\
\hline SPAC19G12.16c (adg2) & $1.4 \pm 0.18$ \\
\hline SPAC110.01 (ppk1) & $5.8 \pm 0.67$ \\
\hline SPBC1348.01 (Schizosaccharomyces pombe-specific DUF999 protein family 5) & $0.9 \pm 0.05$ \\
\hline SPCC736.14 (dis1) & $0.7 \pm 0.07$ \\
\hline
\end{tabular}

Average fold changes in expression levels were calculated relative to the untreated control. Data are representative of three independent experiments.

\section{DISCUSSION}

Because of their redox potential, copper ions play an important role as a cofactor in various proteins. On the other hand, excess copper can damage cellular compartments and macromolecules and change their structure and function (Eide, 1998). In humans, many copper-related disorders have been identified. From prokaryotes to higher eukaryotes, many organisms have developed tight control systems to maintain the delicate balance between the usefulness and toxicity of copper. Although many copper-related proteins have been defined in various cell types, we still need to explore new proteins or mechanisms to better understand how cells utilize copper or cope with its toxicity. Accordingly, the determination of the functions and interactions of the proteins related to copper metabolism, directly or indirectly, is very important.

First, the $\mathrm{EC}_{50}$ value of $\mathrm{CuSO}_{4}$ was determined. In EMM, $50 \mu \mathrm{M} \mathrm{CuSO}_{4}$ led to halfmaximal growth inhibition (50\%) of $S$. pombe cells at the end of $24 \mathrm{~h}$. Growth inhibition and cell death caused by excess copper have also been shown in S. cerevisiae, Caenorhabditis 
elegans and MCF7 mammalian cancer cells (Ostrakhovitch and Cherian, 2005; Liang and Zhou, 2007; Wang et al., 2009). After defining the $\mathrm{EC}_{50}$ value of copper as $50 \mu \mathrm{M} \mathrm{CuSO}_{4}$, differential gene expression at this $\mathrm{CuSO}_{4}$ concentration versus control conditions was determined by DD performed as described above. Differential bands were sent for sequence analysis. Of the 25 bands, 5 bands considerably matched the $S$. pombe genome. These genes, SPCC1682.13 (laf2,), SPAC110.01 (ppk1), SPBC2F12.05c (sterol binding ankyrin repeat protein), SPAC19G12.16c (adg2), SPBC1348.01 (conserved protein), were then subjected to quantitative real-time PCR analysis. Compared to the control group, 1.6-, 5.8-, 1.4-, 1.4-fold increases in gene expression were detected under copper stress, respectively. SPBC1348.01 had reduced expression ( 0.9 -fold) and was regarded as a false positive.

The SPCC1682.13 gene, which showed a 1.6-fold increase in gene expression, encodes the SWIRM domain containing Clr6-associated factor 2 (Laf2) in S. pombe. The protein is present in Rpd3L-expanded and Rpd3S complexes and functions together with the main histone deacetylase Clr6 (Da et al., 2006; Shevchenko et al., 2008). In the absence of histone deacetylases, chromosome segregation abnormalities and sensitivity to DNA-damaging agents have been shown in $S$. pombe (Grewal et al., 1998). It is known that Clr6 has a role in chromatin organization through deacetylation of $\mathrm{H} 3$ and $\mathrm{H} 4$ histone proteins (Grewal, 2000). SWIRM domain is evolutionary well conserved among eukaryotes and is present in proteins that have a role in the regulation of gene expression and chromatin organization (Qian et al., 2005). Structural analysis of the domain has shown that it has high sequence similarity with the DNA-binding region of regulatory proteins. Moreover, it has been stated that SWIRM domain has high affinity for the nucleosomal region (Da et al., 2006). When the other proteins that function together with Clr6 were investigated, some new proteins were revealed that have a role in chromosome condensation and resolution events. For example, Nakayama et al. (2003) showed that when the Pst2-encoding gene was deleted, acetylation of H3 and H4 histone proteins was increased and that deacetylation could not be successfully completed. Besides, during mitosis, some errors occurred in chromosome condensation/resolution events, and sensitivity to DNA-damaging agents in the pst2 gene-deleted strains was also observed (Nakayama et al., 2003). More recently, Kunoh et al. (2008) showed that when any factor leads to deceleration of DNA replication, $\mathrm{H} 4$ deacetylation may play an important role in the regulation of cell cycle.

In this study, $50 \mu \mathrm{M}$ was determined as the $\mathrm{EC}_{50}$ for $\mathrm{CuSO}_{4}$, which caused considerable growth inhibition. One of the most important forms of copper toxicity-related cellular damage is known to be DNA damage. According to our results, the inhibition of cell division and possible DNA damage because of copper toxicity may lead to increased expression of the laf2 gene, which functions with Clr6. When the consequences of Pst2 absence are considered, it can be hypothesized that Laf 2 has a similar importance in the regulation of the cell cycle in response to copper stress in $S$. pombe cells.

The SPAC110.01 (ppk1) gene, whose expression was increased 5.8-fold under copper stress, putatively encodes a serine/threonine protein kinase in S. pombe. Although there has been no comprehensive investigation of its cellular functions, it is known that it has two orthologs in S. cerevisiae (http://www.genedb.org/genedb/pombe). The first one, YOR223W (KIN4), has an inhibitory effect on MEN. In this way, a cell can save time to correct spindle misalignment (Pereira and Schiebel, 2005). The second one is thought to be a protein kinase but it has not yet been characterized (Huh et al., 2003). During cell division accurate chromo- 
some segregation is very important. In S. cerevisiae, it has been shown that the KIN4 protein is expressed throughout the entire cell cycle, but when spindle mislocalization occurs it is activated and binds to microtubules, thereby repressing MEN (Lew and Burke, 2003). Pereira and Schiebel (2005) observed that although spindle mislocalization occurred, mitosis continued but with the formation of nucleus-free cells in KIN4 mutant S. cerevisiae cells.

Wang and Huffaker (1997) determined that the Stu2 protein, which has a role in microtubule formation, can bind to spindles and ensures accurate spindle positioning in $S$. cerevisae. Kosco et al. (2001) later showed that STU2-deleted cells displayed spindle misalignment and chromosome mislocalization. They also observed that copper addition to the medium inhibited STU2 mRNA synthesis and degraded existing Stu2 proteins. According to that study, cells had buds but chromosome segregation was not achieved under copper stress. As a consequence of copper toxicity, these cells had defective or lower levels of microtubules and showed spindle misalignments (Kosco et al., 2001). Taken together, these data led us to think that the 5.8-fold increase in ppk1 gene expression under copper stress can be explained by similar mechanisms. To test this possibility, we examined dis1 gene expression (the ortholog of S. cerevisiae STU2 ortholog in $S$. pombe) under the same conditions and found that dis1 expression level was reduced by $30 \%$. This observation supports the idea that microtubule degradation depends on spindle misalignment, which induces ppk1 expression. Thus, cells can inhibit the septation initiation network (SIN), which is an MEN-like complex in S. pombe, and cell division can be repressed. This may lead to growth retardation. Moreover, because of spindle mislocalization, Laf2 gene expression may be induced as a part of corrective mechanisms.

SPBC2F12.05c putatively encodes the sterol binding ankyrin repeat protein. Despite the fact that we did not encounter any published study that investigated the role of the protein in S. pombe, S. cerevisiae has three orthologs of the gene (http://www.genedb.org/genedb/ pombe). OSH1, OSH2 and OSH3 proteins are the members of the oxysterol-binding proteins. These proteins mainly function as intracellular sterol transporters (Raychaudhuri et al., 2006). Howlett and Avery (1997) showed in S. cerevisiae that lipid peroxidation levels were elevated in cell membranes when cells were treated with excess copper. In addition, it has been shown that liver toxicity that was caused by copper-rich diet in mice resulted in an increase in sterol transporter protein production (Muller et al., 2007). Svensson et al. (2003) found a similar copper response in macrophages. Thus, a 1.4-fold increase in SPBC2F12.05c gene expression under copper stress can be explained by a similar mechanism.

On the other hand, it has been shown in mammals that OSB proteins can affect signaling pathways by directly interacting with PP2A serine/threonine phosphatase and PTPPBS tyrosine phosphatase (Wang et al., 2005). Recently, Chan and Amon (2009) showed that PP2A acts as a regulator of KIN4 activity in $S$. cerevisiae. Therefore, it can be inferred that sterol binding ankyrin repeat protein may also function together with a PP2A homolog protein to regulate ppk1 activity in $S$. pombe.

A conserved fungal protein encoding gene, adg2, whose expression increased 1.4-fold in response to copper stress in our study is regulated by Ace 2 transcription factor and thought to function in separating daughter cells at the end of cytokinesis (Alonso-Nunez et al., 2005). Ace2p also plays a regulatory role in the cell separation process after budding in $S$. cerevisiae. Butler and Thiele (1991) described that Ace2p transcriptionally activates Cup1 metallothionein, which detoxifies excess copper. Thus, we can hypothesize that increased adg2 expression is an indirect result of Ace $2 p$ gene expression. To test this possibility, copper-responsive 
Ace 2 gene expression and the relationship between Ace2 and other copper-responsive proteins should be investigated. Simanis (2003) stated that besides this regulatory function, Ace2p contributes to a process that represses MEN in S. cerevisiae. The protein carries out this function by inducing the CST13 gene, which encodes an MEN repressor protein, Amn1p. Interestingly, it has been mentioned that Amn1p also contributes to cellular copper sensitivity (http://www. genedb.org/genedb/cerevisiae). These data suggested that Ace2p may also serve as an SIN repressor protein in $S$. pombe.

Taken together, the increase in the expression of the SPCC1682.13, SPBC2F12.05c, adg2, and ppk1 genes seems to be related especially to cell cycle regulation. DNA microarray studies in rat liver cells (Huster et al., 2007), Chlamydomonas reinhardtii (Jamers et al., 2006) and S. cerevisiae (Yasokawa et al., 2008) demonstrated that expression levels of cell cycle regulatory genes were elevated in response to copper toxicity. According to our results, copper ions damage the cell membrane and abolished the functions and structures of proteins, especially cell cycle regulatory proteins. Particularly, proteins that function in chromatin and microtubule misalignment organization are negatively affected. This leads to repression of mitotic exit, which is necessary to correct chromosome segregation abnormalities, and as a result, cell growth slows down. Overlapping functions of the genes we tested support this scenario. However, the verification of this hypothesis is necessary with new experimental approaches.

\section{ACKNOWLEDGMENTS}

Research supported by the Research Fund of Istanbul University (Project \#T747/13092005, \#UDP-4206).

\section{REFERENCES}

Alonso-Nunez ML, An H, Martin-Cuadrado AB, Mehta S, et al. (2005). Ace2p controls the expression of genes required for cell separation in Schizosaccharomyces pombe. Mol. Biol. Cell 16: 2003-2017.

Burstein E, Ganesh L, Dick RD, van De Sluis B, et al. (2004). A novel role for XIAP in copper homeostasis through regulation of MURR1. EMBO J. 23: 244-254.

Butler G and Thiele DJ (1991). ACE2, an activator of yeast metallothionein expression which is homologous to SWI5. Mol. Cell Biol. 11: 476-485.

Chan LY and Amon A (2009). The protein phosphatase 2A functions in the spindle position checkpoint by regulating the checkpoint kinase Kin4. Genes Dev. 23: 1639-1649.

Da G, Lenkart J, Zhao K, Shiekhattar R, et al. (2006). Structure and function of the SWIRM domain, a conserved protein module found in chromatin regulatory complexes. Proc. Natl. Acad. Sci. U. S. A. 103: 2057-2062.

Eide DJ (1998). The molecular biology of metal ion transport in Saccharomyces cerevisiae. Annu. Rev. Nutr. 18: 441-469.

Grewal SI (2000). Transcriptional silencing in fission yeast. J. Cell Physiol. 184: 311-318.

Grewal SI, Bonaduce MJ and Klar AJ (1998). Histone deacetylase homologs regulate epigenetic inheritance of transcriptional silencing and chromosome segregation in fission yeast. Genetics 150: 563-576.

Howlett NG and Avery SV (1997). Induction of lipid peroxidation during heavy metal stress in Saccharomyces cerevisiae and influence of plasma membrane fatty acid unsaturation. Appl. Environ. Microbiol. 63: 2971-2976.

Huh WK, Falvo JV, Gerke LC, Carroll AS, et al. (2003). Global analysis of protein localization in budding yeast. Nature 425: 686-691.

Huster D, Purnat TD, Burkhead JL, Ralle M, et al. (2007). High copper selectively alters lipid metabolism and cell cycle machinery in the mouse model of Wilson disease. J. Biol. Chem. 282: 8343-8355.

Ivanova AV and Ivanov SV (2002). Differential display analysis of gene expression in yeast. Cell Mol. Life Sci. 59: 12411245.

Jamers A, Van der Ven K, Moens L, Robbens J, et al. (2006). Effect of copper exposure on gene expression profiles in Chlamydomonas reinhardtii based on microarray analysis. Aquat. Toxicol. 80: 249-260. 
Karlström AR and Levine RL (1991). Copper inhibits the protease from human immunodeficiency virus 1 by both cysteine-dependent and cysteine-independent mechanisms. Proc. Natl. Acad. Sci. U. S. A. 88: 5552-5556.

Kosco KA, Pearson CG, Maddox PS, Wang PJ, et al. (2001). Control of microtubule dynamics by Stu2p is essential for spindle orientation and metaphase chromosome alignment in yeast. Mol. Biol. Cell 12: 2870-2880.

Kunoh T, Habu T and Matsumoto T (2008). Involvement of fission yeast Clr6-HDAC in regulation of the checkpoint kinase Cds1. Nucleic Acids Res. 36: 3311-3319.

Lew DJ and Burke DJ (2003). The spindle assembly and spindle position checkpoints. Annu. Rev. Genet. 37: 251-282.

Liang P and Pardee AB (2003). Analysing differential gene expression in cancer. Nat. Rev. Cancer 3: 869-876.

Liang Q and Zhou B (2007). Copper and manganese induce yeast apoptosis via different pathways. Mol. Biol. Cell 18: 4741-4749.

Muller P, van Bakel H, van De Sluis B, Holstege F, et al. (2007). Gene expression profiling of liver cells after copper overload in vivo and in vitro reveals new copper-regulated genes. J. Biol. Inorg. Chem. 12: 495-507.

Nakayama J, Xiao G, Noma K, Malikzay A, et al. (2003). Alp13, an MRG family protein, is a component of fission yeast Clr6 histone deacetylase required for genomic integrity. EMBO J. 22: 2776-2787.

O’Connor JM (2001). Trace elements and DNA damage. Biochem. Soc. Trans. 29: 354-357.

Ostrakhovitch EA and Cherian MG (2005). Role of p53 and reactive oxygen species in apoptotic response to copper and zinc in epithelial breast cancer cells. Apoptosis 10: 111-121.

Pena MM, Lee J and Thiele DJ (1999). A delicate balance: homeostatic control of copper uptake and distribution. J. Nutr. 129: $1251-1260$.

Pereira G and Schiebel E (2005). Kin4 kinase delays mitotic exit in response to spindle alignment defects. Mol. Cell 19: 209-221.

Pfaffl MW (2001). A new mathematical model for relative quantification in real-time RT-PCR. Nucleic Acids Res. 29 : e45.

Qian C, Zhang Q, Li S, Zeng L, et al. (2005). Structure and chromosomal DNA binding of the SWIRM domain. Nat. Struct. Mol. Biol. 12: 1078-1085.

Raychaudhuri S, Im YJ, Hurley JH and Prinz WA (2006). Nonvesicular sterol movement from plasma membrane to ER requires oxysterol-binding protein-related proteins and phosphoinositides. J. Cell. Biol. 173: 107-119.

Shevchenko A, Roguev A, Schaft D, Buchanan L, et al. (2008). Chromatin central: towards the comparative proteome by accurate mapping of the yeast proteomic environment. Genome Biol. 9: R167.

Simanis V (2003). The mitotic exit and septation initiation networks. J. Cell Sci. 116: 4261-4262.

Svensson PA, Englund MC, Markström E, Ohlsson BG, et al. (2003). Copper induces the expression of cholesterogenic genes in human macrophages. Atherosclerosis 169: 71-76.

Tawe WN, Eschbach ML, Walter RD and Henkle-Duhrsen K (1998). Identification of stress-responsive genes in Caenorhabditis elegans using RT-PCR differential display. Nucleic Acids Res. 26: 1621-1627.

Theophanides T and Anastassopoulou J (2002). Copper and carcinogenesis. Crit. Rev. Oncol. Hematol. 42: 57-64.

Tullo A and Sbisà E (2002). Molecular characterization of p53 mutations in primary and secondary liver tumors: diagnostic and therapeutic perspectives. Mol. Biotechnol. 21: 265-278.

Waggoner DJ, Bartnikas TB and Gitlin JD (1999). The role of copper in neurodegenerative disease. Neurobiol. Dis. 6: 221-230.

Wang PJ and Huffaker TC (1997). Stu2p: A microtubule-binding protein that is an essential component of the yeast spindle pole body. J. Cell Biol. 139: 1271-1280.

Wang PY, Weng J and Anderson RG (2005). OSBP is a cholesterol-regulated scaffolding protein in control of ERK $1 / 2$ activation. Science 307: 1472-1476.

Wang S, Wu L, Wang Y, Luo X, et al. (2009). Copper-induced germline apoptosis in Caenorhabditis elegans: the independent roles of DNA damage response signaling and the dependent roles of MAPK cascades. Chem. Biol. Interact. 180: 151-157.

Yasokawa D, Murata S, Kitagawa E, Iwahashi Y, et al. (2008). Mechanisms of copper toxicity in Saccharomyces cerevisiae determined by microarray analysis. Environ. Toxicol. 23: 599-606. 